1994-4

\title{
Investigating the Age Effects of Family Structure on Adolescent Marijuana Use
}

John P. Hoffmann

Brigham Young University - Provo, john_hoffmann@byu.edu

Follow this and additional works at: https://scholarsarchive.byu.edu/facpub

Part of the Family, Life Course, and Society Commons, Medicine and Health Commons, and the Social Control, Law, Crime, and Deviance Commons

\section{Original Publication Citation}

Hoffmann, John P. 1994. "Investigating the Age Effects of Family Structure on Adolescent Marijuana Use." Journal of Youth and Adolescence 23(2): 215-235.

\section{BYU ScholarsArchive Citation}

Hoffmann, John P., "Investigating the Age Effects of Family Structure on Adolescent Marijuana Use" (1994). Faculty Publications. 3957.

https://scholarsarchive.byu.edu/facpub/3957

This Peer-Reviewed Article is brought to you for free and open access by BYU ScholarsArchive. It has been accepted for inclusion in Faculty Publications by an authorized administrator of BYU ScholarsArchive. For more information, please contact ellen_amatangelo@byu.edu. 
Investigating the age effects of family structure on adolesc

Journal of Youth and Adolescence; Apr 1994; 23, 2; ProQuest

pg. 215

\section{Investigating the Age Effects of Family Structure on Adolescent Marijuana Use}

John P. Hoffmann ${ }^{1}$

Received June 24, 1992; accepted April 6, 1993

This study examines differences among older and younger adolescents in the influence of family structure, family relations, and peer relations on marijuana use. Data from a longitudinal sample of adolescents from the United States were stratified by age and used to assess these potential differences. Precise measures of family structure were constructed to account for the various manifestations of family forms. Multivariate analyses indicate that a recent divorce attenuates attachment among younger adolescents and leads to less family involvement among older adolescents. Moreover, older adolescents from stepparent families are less attached to their families. Changes in these family relationship variables influence associations with drug using peers, but these processes differ for the two age groups. Finally, less family involvement and greater drug using peer associations lead to greater marijuana use among younger adolescents, while only peer associations directly affect use among older adolescents.

This research was partially funded by a Faculty Research Grant provided by the University of North Carolina-Charlotte. The data used in this paper were made available by the Inter-university Consortium for Political and Social Research. The data for the National Youth Survey, 1976 to 1978 (Waves 1-3), were originally collected by Delbert Elliott and colleagues at the Institute of Behavioral Science. Neither the collectors of the original data nor the consortium bear any responsibility for the analyses or interpretations presented here. ${ }^{1}$ Post-Doctoral Fellow, Emory University School of Public Health, Atlanta, Georgia, and Assistant Professor, Department of Criminal Justice, UNC-Charlotte. Received Ph.D. from the State University of New York at Albany. Current research interests include adolescent drug use, social-psychological determinants of violence, and behavioral aspects of HIV transmission. 


\section{INTRODUCTION}

The past several years have seen a resurgence in research on the family's influence on drug using and delinquent behavior. In particular, a number of studies have focused on family structural effects on drug use and general delinquency (Mednick, et al., 1990; Flewelling and Bauman, 1990; Needle et al., 1990; Farnworth, 1984). Although the "broken homes" hypothesis has existed for several decades (see Wells and Rankin, 1991), it has only been in recent years that studies have paid greater attention to conceptualizing family structure and its potential influences on drug use and delinquency. For example, research demonstrates that the effects of divorce and remarriage on adolescent drug use are distinct (Needle et al., 1990). and that the timing of divorce is important when assessing delinquency and adult criminality (Mednick et al., 1990).

In addition, general family studies of drug use and delinquency illustrate the need for a more detailed focus on age distinctions (Bailey and Hubbard, 1990; LaGrange and White, 1985). Research indicates that family relational and structural influences on adolescent drug use shift as one moves through adolescence. Given the often turbulent nature of adolescence, it is not surprising that the influence of the family changes. Unfortunately, few studies have explored these alterations in any detail. The objective of this paper is to investigate the effects of family structure, family relations, and peer relations on one particular form of adolescent drug use-marijuana use-yet to do so in an age-specific context.

\section{PREVIOUS LITERATURE}

Extant literature on adolescent marijuana use suggests that the family, in particular family relations, plays a limited role (Kandel, 1980; Kandel $e t$ al., 1978). Strong family relations provide some restraint on adolescent marijuana use, but the vast majority of research indicates that peer associations are the strongest influence on this form of behavior (e.g., Kandel, 1978; Elliott et al., 1985; Hundlesby and Mercer, 1987; Johnson et al., 1987). Much of this research, however, fails to investigate the relationship between family relations, peer associations, and adolescent marijuana use by age. In light of the common conclusion that, as one moves through adolescence, influences on attitudes and behavior change from parents to peers (Berndt, 1979; Forehand et al., 1988), it is clear that a developmental shift in influence on marijuana use from families to peers may occur.

Two notable exceptions in the literature that address this issue support the contention that a developmental shift occurs during adolescence. 
Huba and Bentler (1980) and Bailey and Hubbard (1990) find that parental influences on drug use diminish while peer influences increase throughout early and mid-adolescence. Bailey and Hubbard (1990) explore these processes in detail and determine that better parent-child relations decrease the probability of marijuana initiation among sixth- to eight-grade adolescents, yet have no direct influence on ninth-grade adolescents. Peer relations, on the other hand, become influential around the eighth grade and continue to affect marijuana initiation in the ninth grade. Peer marijuana use significantly increases the probability of marijuana initiation among eight- and ninth-grade youths. Later research by the same authors indicates that peer influences are significant through the ninth grade, but that their effect dissipates (Bailey and Hubbard, 1991). These studies, however, fail to explore family and peer relationships in later adolescence.

\section{Age Effects of Family Structure}

A number of studies indicate that family structure has a significant impact on adolescent marijuana use. Adolescents from intact homes (i.e., two natural parents reside in the home) are less likely to use marijuana and tend to use less frequently than adolescents from nonintact homes (e.g., single parent or stepparent homes; Wallace and Bachman, 1991; Wells and Rankin, 1991; Needle et al., 1990; Flewelling and Bauman, 1990; Selnow, 1987; Smith and Paternoster, 1987). Nevertheless, these studies typically indicate that family structure has a modest effect. This research has not investigated potential age differences when assessing marijuana use, though. In fact, Amato and Keith's (1991) meta analysis of the general effects of divorce on child and adolescent well-being indicates that few studies compare age groups. Those that have indicate that divorce has the most detrimental impact on social adjustment and parent-child relations among primary and secondary school age children (presumably 12-17 years of age). These studies, however, tell us little about the effects of other types of family structure, such as stepparent families or widowed parent families.

Research that has focused specifically on drug use and delinquency supports the contention that divorce has its greatest impact during adolescence. Mednick et al. (1990) discover that parental divorce during adolescence leads to a significant increase in the probability of delinquency and young adult criminality. Nonetheless, their study relied on official data (cf. DeFleur, 1975) and did not distinguish marijuana or other forms of drug use.

Needle et al. (1990) determine that a divorce during adolescence leads to greater drug involvement among boys, while a remarriage leads to in- 
creased drug use among girls. A divorce during childhood has no significant effect on drug use among either group. The coefficients upon which they rely for their positive findings, however, are only marginally significant at the .10 level. Moreover, the authors do not evaluate other reasons for family disruption (e.g., death of a parent) or differences between adolescent age groups. Given that the effects of family relations, peer relations, and family structure fluctuate during adolescence (Bailey and Hubbard, 1990; Hetherington et al., 1989), it is clear that an assessment of these influences should be considered in an age-specific context.

\section{THEORETICAL FRAMEWORK}

The theoretical model underpinning this research suggests that the lackluster effects of family structure on adolescent marijuana use found in previous studies is due to a lack of attention to intervening processes (Forgatch et al., 1988; Matsueda and Heimer, 1987). Studies that have compared the effects of family structure and family relations, for example, find that the latter have a much stronger influence on adolescent marijuana use (White et al., 1987; Van Voorhis et al., 1988; Selnow, 1987). Some suggest that family structure is therefore not important; rather, one should focus on relations within the family when assessing marijuana use (e.g., Van Voorhis et al., 1988). This conclusion, however, ignores the substantial research which indicates that family structure affects family relations (Amato and Keith, 1991; Hetherington et al., 1982; Furstenberg and Cherlin, 1991). It also relies on research that has operationalized family structure merely as a dichotomy (i.e., intact vs. nonintact families). Family structure may take a variety of forms such as divorced single-parent homes, stepparent homes, and widowed parent homes (Kellam et al., 1982). Each has been found to have differing effects on family relations and adolescent conduct (Hetherington et al., 1989; Johnson, 1986; Nelson, 1982). These various forms of family structure may not have a direct effect on marijuana use, but rather an indirect effect mediated by family and parent-child relations.

In addition, the finding that peer relations provide the most proximate influence on marijuana use may reflect the indirect effect of family relations. Family and parent-child relations have a recognizable influence on peer choice: poor relations with parents often allow adolescents a greater variety of peer choices, thus increasing the probability of associating with deviant peers (Brook et al., 1990; Thornberry, 1987; Elliott et al., 1985; Simons and Robertson, 1989). Drug using peers increase the likelihood of marijuana use by providing models and reinforcement for this form of behavior. In addition, family relations can act to control marijuana use di- 
rectly by providing strong ties to conventional society (cf. Hirschi, 1969), but their influence is modest when compared to the effects of drug using peers.

A visual representation of the theoretical model is provided in Fig. 1. Based upon previous literature, family structure is broken down into six constituents. Since a recent divorce has the most detrimental effect on youths (Hetherington et al., 1982), it is distinguished from divorced, singleparent homes. Stepparents have been found to improve family relations somewhat, although they do not tend to reach predivorce levels (IhingerTallman, 1988; Furstenberg and Cherlin, 1991). Finally, parent/other adult homes and widowed parent homes have been given scant attention in the research literature, but may have distinct effects on adolescents (Nelson, 1982; Kellam et al., 1982). A parent's death, in particular, does not tend to damage parent-child relations, but it does lead to bereavement that may affect family involvement (Lehman et al., 1989).

Data limitations restrict us to two measures of family relations: affectional attachment and involvement. Both are affected by family structure. Divorce and remarriage, in particular, tend to damage affectionate relations between parents and children, while single-parent homes provide fewer opportunities for parent-child involvement (Hetherington et al., 1982; Peterson and Zill, 1986; Amato, 1987; Mednick et al., 1990). Attenuated levels of attachment and involvement increase the likelihood of associating with drug using peers, and thus can lead to potentially greater marijuana use both directly and indirectly.

Although this model provides one general path toward adolescent marijuana use, its implications for different adolescent age groups are unclear. Previous literature provides little guidance concerning the age-specific effects of family structure, although a divorce or remarriage may have its most detrimental effects during early adolescence (Amato and Keith, 1991; Hetherington et al., 1989). Older adolescents are better able to cope with family disruption due to their greater maturity and independence (cf. Amato and Keith, 1991). There is, however, little empirical literature addressing this proposition.

As mentioned above, the few studies that have addressed age differences in family and peer relations indicate that younger adolescents are affected greater by the former and older adolescents by the latter when assessing marijuana use (Huba and Bentler, 1980; Bailey and Hubbard, 1990). Berndt (1979) finds, however, that peer influences on antisocial behavior are most pronounced up to age 15 , but then decrease throughout senior high school. When coupled with research suggesting that parentchild relational restraints over delinquent conduct also dissipate after age 15 (LaGrange and White, 1985), it appears that the model will be best 


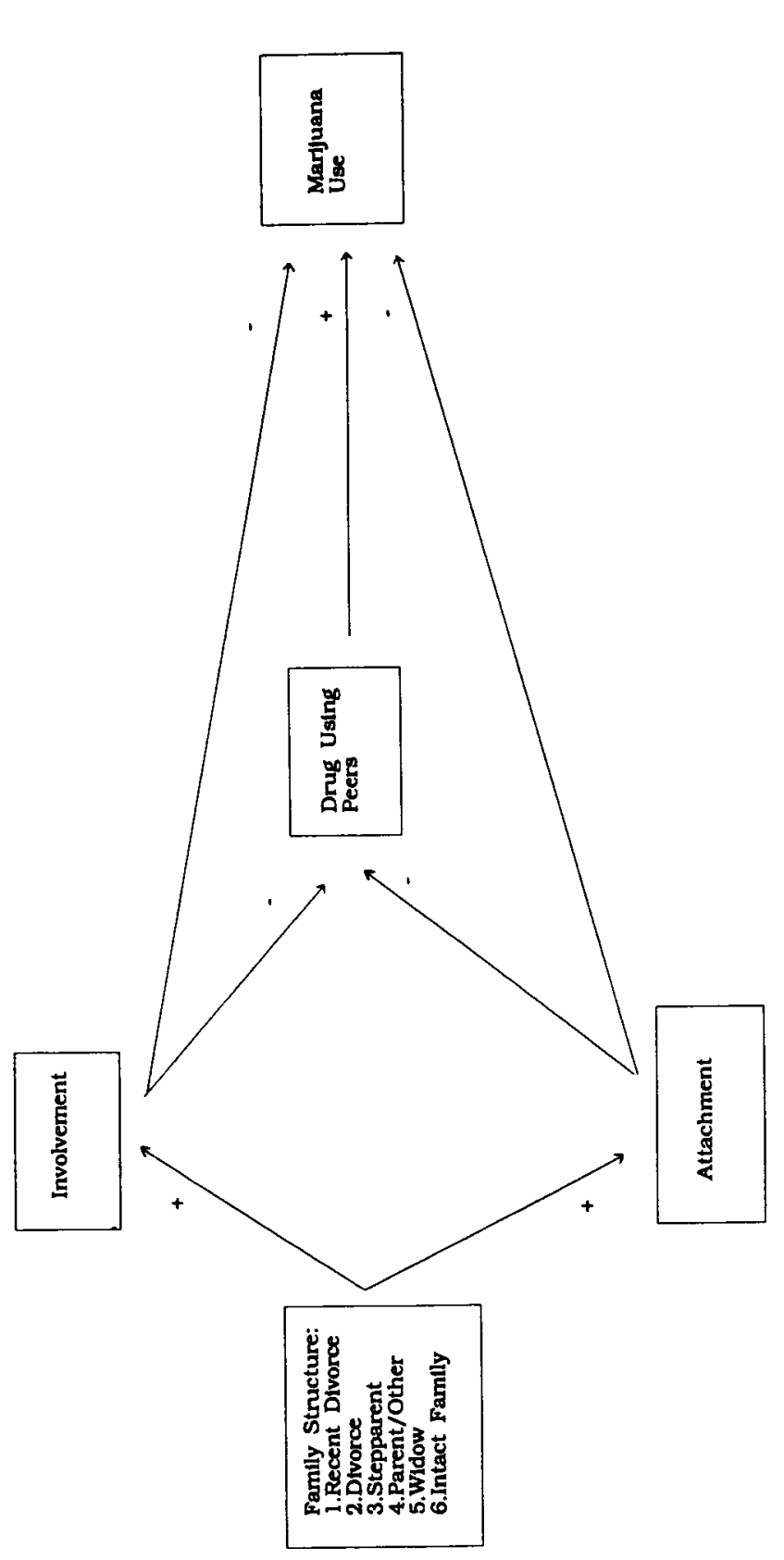


suited for younger adolescents. Nevertheless, an empirical assessment is needed to investigate the plausibility of this assertion.

\section{DATA AND METHODS}

The data utilized to assess the model are derived from the National Youth Survey (NYS; see Elliott et al., 1985, and Elliott et al., 1983, for a thorough description). The NYS is a longitudinal study of drug use and delinquency among multiple cohorts of adolescents from the United States. The initial sample, selected in 1976, consisted of a national probability sample of adolescents ages 11-17 $(n=1725)$. The total youth sample was interviewed in early 1977 about events that occurred and conditions that were present during 1976. Furthermore, one parent or guardian was interviewed during the first year. Interviews were also conducted with the adolescents during the following three years. This study is restricted to the first three years of data (1977-1979).

The use of longitudinal data allows one to detect the temporal order of variables with greater accuracy (Menard, 1991). Thus, we may determine the effect of earlier parent-child and peer relations on subsequent marijuana use. In addition, by measuring them during consecutive years, the change in these variables can be evaluated. An equation of the following form, $Y_{t}=a+b_{1} X_{t-1}+b_{2} X_{t}+b_{3} Y_{t-1}+e$, for example, allows one to estimate the effect of a change in $X$ (e.g., decrease in attachment) on a change in $Y$ (e.g., increase in drug using peers; Plewis, 1985). By deleting $X_{t}$, one may also assess the effects of a previous level of a variable on ensuing changes in the dependent variable. For example, one can estimate the effects of family structure during the first year of subsequent changes in parent-adolescent attachment.

Family structure is measured by a group of mutually exclusive dummy variables. Questions concerning which adults were living in the home and the cause of any family disruption were asked of the parent or guardian during the initial interview. By manipulating the responses to these questions, the following types of families were isolated: recently divorced (within the previous year, $n=63)$; divorced, single-parent family $(n=100)$; stepparent family ( $n=147)$; parent/other adult family $(n=93)$; widowed, single-parent family $(n=40)$; and two natural parent family (intact, $n=1178)$. An "other" category is included in the analyses $(n=104)$, but since it contains such a diverse group of family types, it is left out of subsequent discussions. In the analyses, intact families are excluded as the reference category.

The two family relationship variables, attachment and involvement, are measured by multiple questions asked of the adolescent respondents 
during each interview. Principal components analysis was utilized to derive parsimonious measures of these variables. Appendix A supplies the questions as well as their factor loadings and alpha reliabilities. They are measured so that higher values indicate closer relations between adolescents and their parents and families. Drug using peers is measured by questions concerning peer marijuana use, illicit prescription drug use, and hard drug sales (see Appendix A).

Marijuana use is measured by a single question: "How many times in the past year have you used marijuana?" Responses range from 1 (never) to 9 (two or three times per day). (Drug using peers and marijuana use are both highly skewed. To correct for skewness, both variables were logged. The analyses revealed, however, that logging these variables has little effect on the results. The variables are therefore left in their original metric. In addition, some suggest that additive scales such as those used for the attachment, involvement, and peer measures should be constructed using standardized variables. Standardization of the variables prior to addition did not change the results, and thus the additive scales are constructed using unstandardized variables.)

Since we are concerned with age differences, the sample is stratified into two components, younger adolescents (11-13 during Year 1 and 13-15 during Year 3) and older adolescents (14-17 during Year 1 and 16-19 during Year 3). The division point is approximately at the mean of age (13.87, Year 1).

Several control variables are included in the analyses since family structure and family relationship effects have been found to differ, and may be affected, by sex, race, and socioeconomic status (Amato and Keith, 1991). Race is measured by three dummy variables-White, Black, and Other-with White excluded as the reference category. Socioeconomic status is measured by the Hollingshead scale, with higher values indicating decreasing status.

Table I provides the variable means and standard deviations for the entire sample and by age group for each year during which the variable can be measured. The $t$ tests evaluating differences in means indicate that, generally, involvement and attachment decrease significantly as one moves from younger to older adolescence. Moreover, the number of drug using peers and marijuana use increase as adolescents become older. This occurs both within and between the two age cohorts.

\section{Analytic Procedures}

The first half of each model (younger and older) is estimated with standard path analysis techniques using ordinary least squares (OLS) re- 
Table I. Descriptive Statistics for Variables ${ }^{a}$

\begin{tabular}{|c|c|c|c|c|c|c|}
\hline \multirow[b]{2}{*}{ Variable } & \multicolumn{2}{|c|}{ Entire sample } & \multicolumn{2}{|c|}{ Younger (11-13) } & \multicolumn{2}{|c|}{ Older $(14-17)$} \\
\hline & Mean & SD & Mean & SD & Mean & SD \\
\hline \multicolumn{7}{|l|}{$\begin{array}{l}\text { Substantive } \\
\text { Variables }\end{array}$} \\
\hline Involvement I & 11.23 & 3.12 & $11.74^{* *}$ & 2.89 & $10.81^{* *}$ & 3.23 \\
\hline Involvement II & 10.03 & 3.58 & $10.90^{* *}$ & 3.30 & $9.31^{* *}$ & 3.64 \\
\hline $\begin{array}{l}\text { Involvement III } \\
\text { (range 1-15) }\end{array}$ & 9.74 & 3.70 & $10.71^{* *}$ & 3.36 & $8.92^{* *}$ & 3.78 \\
\hline Attachment I & 21.90 & 4.13 & $22.42^{* *}$ & 3.68 & $21.45^{* *}$ & 4.42 \\
\hline Attachment II & 22.25 & 4.02 & $22.70^{* *}$ & 3.83 & $21.86^{* *}$ & 4.13 \\
\hline $\begin{array}{l}\text { Attachment III } \\
\text { (range 1-29) }\end{array}$ & 22.25 & 4.28 & $22.58^{* *}$ & 4.11 & $21.96^{* *}$ & 4.40 \\
\hline Drug Peers $\mathrm{I}^{b}$ & 1.68 & 1.30 & $1.25^{* *}$ & .84 & $2.03^{* *}$ & 1.48 \\
\hline Drug Peers II & 2.13 & 1.82 & $1.53^{* *}$ & 1.18 & $2.62^{* *}$ & 2.09 \\
\hline $\begin{array}{l}\text { Drug Peers IIl } \\
\text { (range 1-13) }\end{array}$ & 2.75 & 2.16 & $2.07^{* *}$ & 1.80 & $3.31^{* *}$ & 2.28 \\
\hline Marijuana Use I & 1.52 & 1.44 & $1.08^{* *}$ & .46 & $1.90^{* *}$ & 1.82 \\
\hline Marijuana Use II & 1.86 & 1.82 & $1.27^{* *}$ & 1.00 & $2.35^{* *}$ & 2.17 \\
\hline $\begin{array}{l}\text { Marijuana Use III } \\
\text { (range 1-9) }\end{array}$ & 2.30 & 2.20 & $1.65^{* *}$ & 1.60 & $2.86^{* *}$ & 2.46 \\
\hline \multicolumn{7}{|l|}{ Control variables } \\
\hline $\begin{array}{l}\text { Sex } \\
(0=\text { male, } 1=\text { female })\end{array}$ & .46 & .50 & $.50^{*}$ & .50 & $.44^{*}$ & .50 \\
\hline SES & 9.84 & 3.50 & $10.29^{*}$ & 3.52 & $9.92^{*}$ & 3.77 \\
\hline Race: White ${ }^{c}$ & .79 & .41 & .77 & .39 & .81 & .43 \\
\hline Black & .15 & .36 & .16 & .37 & .14 & .35 \\
\hline Other & .06 & .24 & $.07^{*}$ & .25 & $.05^{*}$ & .22 \\
\hline$N$ & 1725 & & 778 & & 947 & \\
\hline
\end{tabular}

${ }^{a}$ Roman numerals indicate the year at which the variable is measured. Drug Peers refer to drug using peers. Adolescents were 11-17 at year 1 and 13-19 at Year 3. Asterisks indicate that the means are significantly different between age groups.

${ }^{b}$ No questions was asked concerning illicit prescription drug use during the first year.

${ }^{c}$ Reference category.

${ }^{*} p<.05 ;{ }^{* *} p<.01$

gression. The effects of family structure on subsequent family relations are assessed. That is, the year two values of attachment and involvement are regressed by family structure. Since the magnitude of betas is minimized when using highly skewed dummy variables such as those that determine family structure, the unstandardized coefficients on the paths from family structure to family relations are also presented. This gives a clearer picture of the effects of family structure (see Glenn and Shelton, 1983).

The paths from family relations to drug using peer associations include changes in both sets of variables; that is, the lagged values of both 
the family relation variables and the peer variable are included in the equation predicting subsequent drug using peers (i.e., both Year 1 and Year 2 are included). This allows us to determine whether a decrease in attachment or involvement is associated with an increase in drug using peers.

Finally, the direct path to marijuana use includes two sets of coefficients. Since the marijuana use measure may suffer from sample selection bias (Berk, 1983), tobit is used to estimate its paths (Amemiya, 1985; Tobin, 1958). (Sample selection bias occurs since one is attempting to predict frequency of use only among a subset of the sample; that is, only among active marijuana users. Those who do not use marijuana are censored from the sample. The model thus attempts to predict marijuana use among a nonrandom subsample. This violates the assumptions of OLS regression and can lead to biased results [Berk, 1983; Little, 1985]. The solution chosen here is to use tobit to estimate marijuana frequency. Tobit separates the effects into the probability of participation vs. nonparticipation [use of marijuana vs. nonuse], and the effects of frequency if there is use [Amemiya, 1985; Maddala, 1983]. One often puts an artificial ceiling on participation [usually by collapsing the top 5\%] to adjust for recall bias. This option did not alter the present results, and therefore marijuana use was left in its original from.) The tobit coefficients are unstandardized, however, and thus betas from an OLS equation are presented in parentheses. Caution is advised since the betas may be biased.

The equations predicting marijuana frequency include the Year 2 and Year 3 marijuana measures (thus measuring the change in this variable), and the Year 2 attachment, involvement, and peer variables. The change in the family and peer variables is not estimated for practical reasons since the survey asks about previous year's marijuana use and current (time of interview) attachment, involvement, and peer drug use. If one included both year three marijuana use and year three peer use, for example, it is possible that one is measuring the effects of marijuana use (which exists between the Time 2 and Time 3 interview) on peer drug use (which exists at the Time 3 interview). Such a situation fails to disentangle the temporal order and leads to unreliable estimates (Baron and Kenny, 1986); thus Year 3 measures of family and peer relations are not included in the equations predicting changes in marijuana use. In sum, we are measuring the effect of family structure (Time 1 ) on subsequent family relations (Time 2); the effect of changes in family relations on changes in peer associations (from Time 1 to Time 2); and the effect of previous levels of family and peer relations (Time 2) on changes in marijuana use (from Time 2 to Time 3 ). 


\section{RESULTS}

Figures 2 and 3 present the results of the analyses for younger and older adolescents. Recall that intact family is the reference category for family structure; thus, the paths represent significant differences between adolescents from these types of families and adolescents from intact families.

The type of family structure has distinct effects on attachment and involvement. A recent divorce, in particular, is associated with less attachment among younger adolescents and less involvement among older adolescents. This supports the notion that the timing of divorce is important (Hetherington et al., 1982), but also suggests that the method of coping is different for younger and older adolescents. In addition, older adolescents from stepparent families manifest lower attachment, yet younger adolescents show no difference compared to those from intact families. This fails to support the view that the adverse effects of stepparent homes disproportionately affect younger adolescents (Hetherington et al., 1989). Adolescents from other types of families do not differ on attachment or involvement when compared to adolescents from natural two-parent homes. In addition, the introduction of control variables has no effect on the results.

Moving through the models, it is clear that, across age groups, family relations have diverse effects on drug using peer associations. For younger adolescents, only attachment affects peer associations; a decrease in attachment leads to an increase in drug using peers. For older adolescents, a decrease in either attachment or involvement results in an increase in the number of drug using peers.

Finally, we find that, as expected, a greater number of drug using peers is associated with a significant increase in marijuana use from one year to the next for both younger and older adolescents. However, the direct family effects are limited to involvement among younger adolescents. Less family involvement leads to an increase in marijuana use from one year to the next. There are no direct effects of family relations on marijuana use among older adolescents, though. This provides further evidence for the view that a transition of influence from families to peers occurs as one moves from early to later adolescence (Huba and Bentler, 1980). Nonetheless, a comparison of the peer effects across models suggests that the influence of peers is weaker among older adolescents (see also Berndt, 1979; cf. Bailey and Hubbard, 1991). Moreover, while family relations may not directly affect marijuana use among older adolescents, they do influence it indirectly through their effects on peers. Strong family relations decrease the number of drug using peers, and this process can consequently 


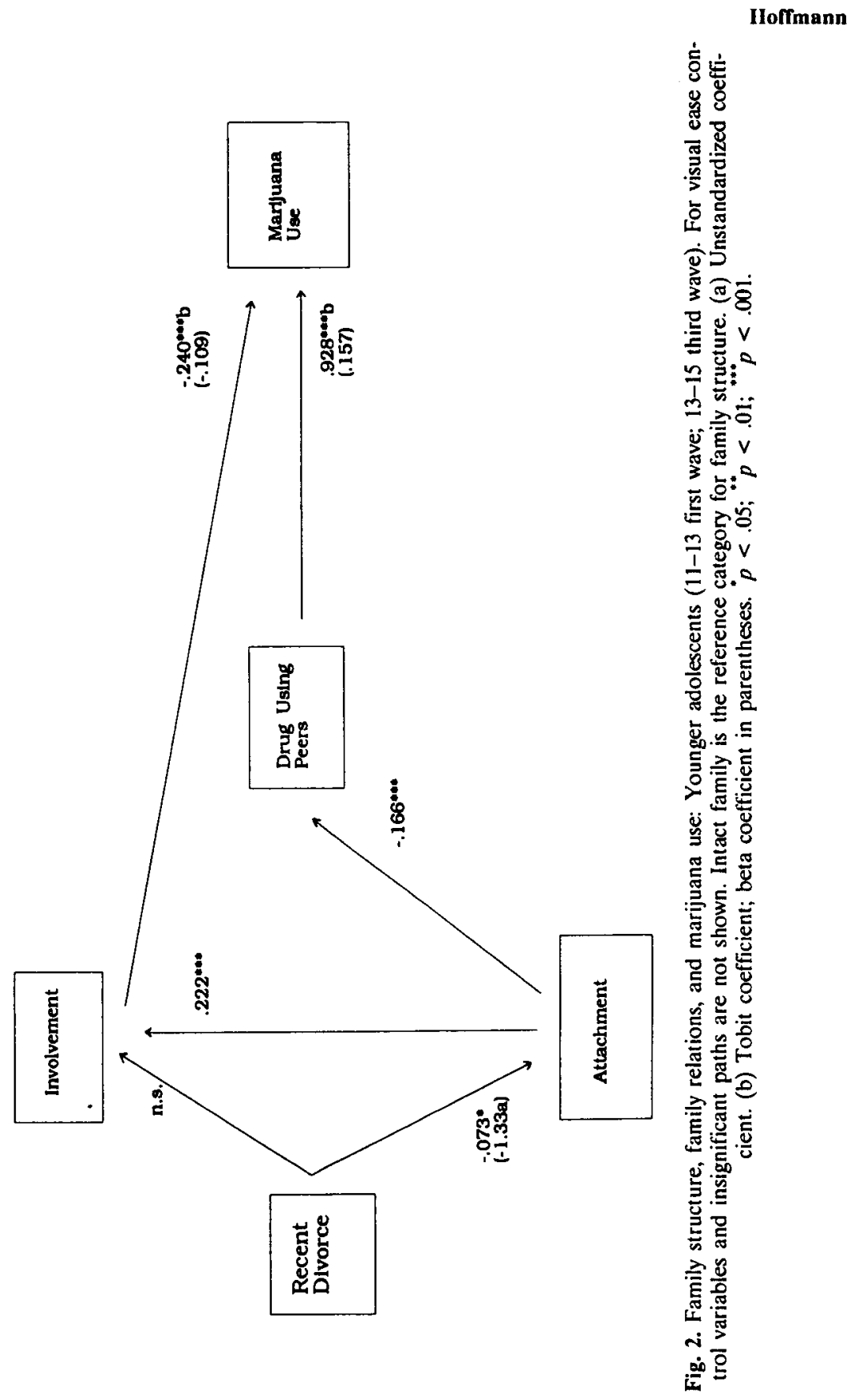



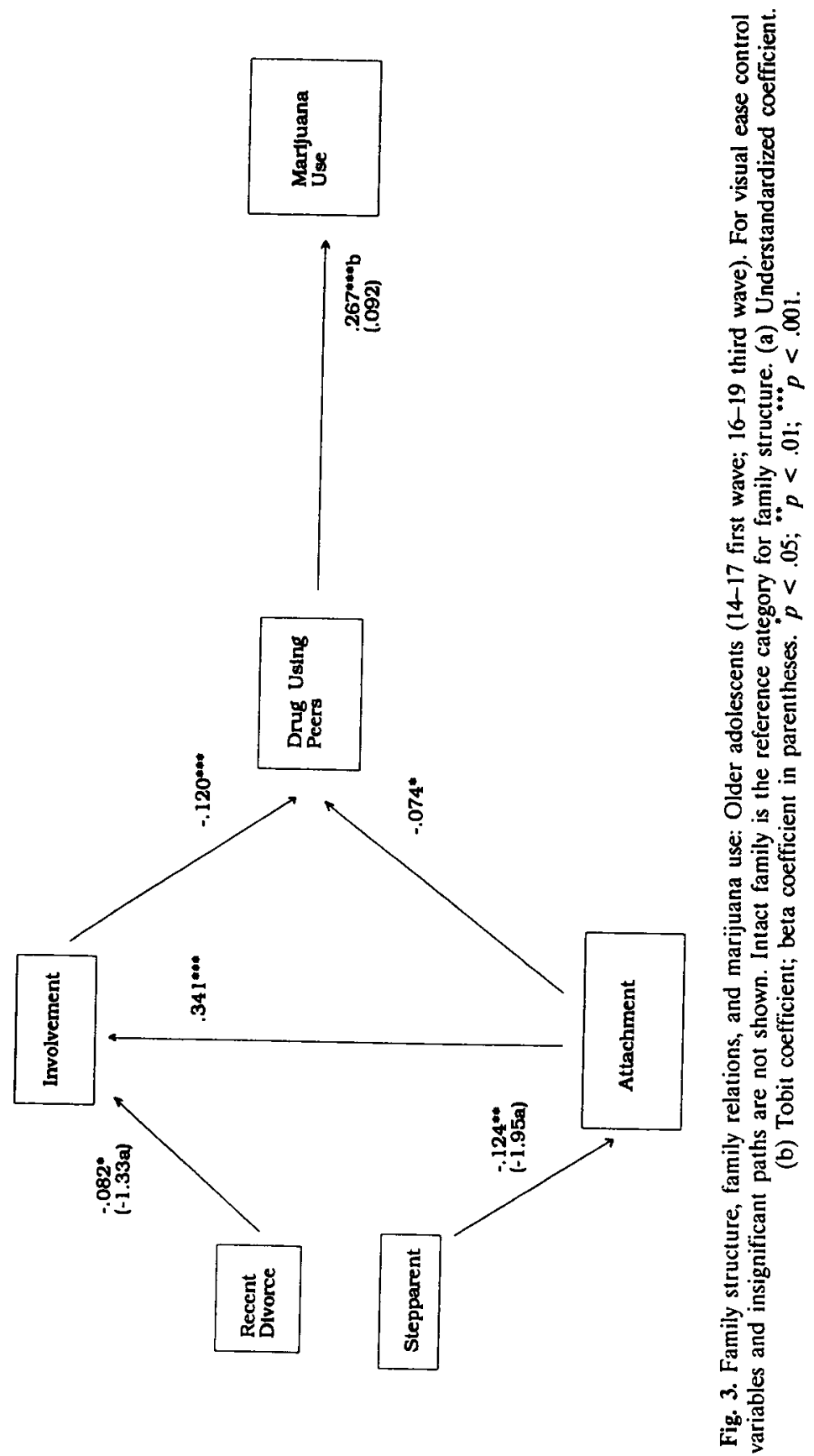
reduce marijuana use. Families may have little direct influence on marijuana use among older adolescents (Bailey and Hubbard, 1990; Huba and Bentler, 1980), but they can affect those peer relations that lead to greater marijuana use.

As a final methodological note, $t$ tests to compare coefficients across equations (Cohen, 1983) were utilized to determine whether the differences between the age groups that appear in the models are significantly distinct. The tests indicate that the only difference that is not significant in the models is that between the effect of attachment on drug using peers $\left(t_{d f=771,940}=1.023\right)$. All other differences across the two age groups are significant.

\section{DISCUSSION}

The findings demonstrate that family structure and family relationship effects on marijuana use during adolescence vary by age. Family structure effects, for example, are limited to those that have drawn the greatest research attention. Divorce and remarriage have particular influences on relations between adolescents and their parents and families. However, as many have suggested, the timing of divorce is an important component.

The present findings suggest that the attenuated relations that result from divorce dissipate over the first two years (see also Hetherington et al., 1982; Hetherington et al., 1989; Wallerstein and Kelly, 1980). These detrimental effects vary by age group, though. Older adolescents respond to divorce by becoming less involved with their family. Since they are generally allowed greater freedom than younger adolescents, this type of response to a stressful event such as divorce is not surprising. Others have labeled such an action as "strategic withdrawal" (Wallerstein and Kelly, 1980). Older adolescents tend to look for support systems outside of the home when divorce occurs (Brody and Forehand, 1988). Unfortunately, a potential outcome of less family involvement is greater involvement with drug using peers, and consequently increasing marijuana use (see also Hetherington, 1987).

For younger adolescents this type of disengagement is not as prevalent. They do not have the same opportunities or freedom to look outside the home for support following a divorce. Therefore, their "strategic withdrawal" consists of less affection for parents. As with older adolescents, this reaction to divorce leads to greater involvement with drug using peer groups and an ensuing increase in marijuana use. 
Although stepparent families do not have as diverse an effect on parent-adolescent relations, they do affect attachment among older adolescents. This finding is in conflict with other research, which intimates that any detrimental impact of remarriage on parent-child relations affects younger adolescents to a greater degree than either preadolescents or older adolescents (Hetherington et al., 1989). It also questions the finding that stepparent effects remain consistent across age groups (Zill, 1988).

Although there is no simple interpretation for these contradictory findings, it appears that older adolescents may feel particularly threatened by the introduction of a stepparent (cf. Johnson, 1986), especially if remarriage has followed a period of good relations between adolescents and single parents. Stepparents typically do not develop as strong an attachment to stepchildren as they do to natural children (Amato, 1987), and this may be recognized with greater clarity by older youths. Since we have no information on the timing of the remarriage, however, it is difficult to assess the precise mechanisms by which these attenuated levels of attachment occur, and it is not possible to determine the levels of attachment prior to the introduction of a stepparent. This information is needed to assess accurately the effects of stepparents on parent-adolescent relations (IhingerTallman, 1988).

The results further support the belief that there is a developmental transition in influence on marijuana use from families to peers (Bailey and Hubbard, 1990; Huba and Bentler, 1980). In light of the indirect family effects among older adolescents, though, this view must be qualified. Any direct effect of family relations may disappear by late adolescence (LaGrange and White, 1985), but family relations, in the form of attachment and involvement, continue to affect associations with peers. A lack of involvement leads directly to an increase in marijuana use among actively using younger adolescents, but among older adolescents this effect is mediated by drug using peers. Therefore, family relations do not become unimportant as one moves through adolescence; rather their influence becomes further removed in the path leading to marijuana use. In addition, as similar research has found (Bailey and Hubbard, 1991; Berndt, 1979), peer effects become relatively weaker as one moves from younger to older adolescence. The net result is that more of the variance in marijuana use is left unexplained. This suggests that additional factors need to be considered if we are to determine the particular routes that affect greater marijuana use among older adolescents.

Several issues need to be addressed in order to advance this type of research. First, as suggested above, there are many additional forms of family relations that may affect adolescent behaviors such as marijuana use. This study is limited to two commonly measured family relationship vari- 
ables (Loeber and Stouthamer-Loeber, 1986), but other research has found that parent-child communication, parental monitoring, and parental discipline also affect adolescent drug use (Dishion and Loeber, 1985; Jensen and Brownfield, 1982; White et al., 1987). If the current findings provide any guidance, these parent-adolescent variables may also influence associations with drug using peers, and may do so in an age-specific context.

Second, recent empirical research on family structure has questioned the presumption that marital disruption intensifies or produces various problems for adolescents. Some research demonstrates that adolescent relations and problem behaviors that appear to be the result of divorce actually are manifest well before family disruption taken place (Cherlin et al., 1991; Doherty and Needle, 1991; Block et al., 1986). This may reflect the fact that dysfunctional families with problem children are merely more likely to divorce. It also suggests that poor family relations can have just as much of a detrimental impact in intact homes, and thus research needs to focus on dysfunction or instability in all types of family structures.

Finally, the issue of reciprocal effects deserves mention. Research suggests that, when assessing adolescent relations and behaviors, a number of reciprocal mechanisms may be at work. Although an investigation of these potential relationships is beyond the scope of this paper, it is important to realize that behaviors such as marijuana use often lead to greater associations with drug using peers (Ginsberg and Greenley, 1978), and may weaken relations between adolescents and their families (Liska and Reed, 1985; Thornberry et al., 1991). Moreover, as family influences diminish during adolescence, deviant peer associations can further attenuate relations with parents and family. This sort of cycle leads to more severe forms of marijuana and other drug use (Brook et al., 1990), and makes the likelihood of intervention more tenuous.

In sum, the effects of family structure, family relations, and peer relations on marijuana use vary by age. In accordance with past research, there is a marked transition in direct influence from families to peers as one progresses through adolescence. This view, however, should be revised to take into account the effects of family relations on peers. These effects are significant and indicate that family relations can impede marijuana use indirectly, even among older adolescents.

Furthermore, family structure has diverse effects on family relations. In accordance with previous research, homes that suffer from divorce, and those that consist of stepparents, are at greater risk for poor parent-child relations. These effects are modest, though, and imply that a divorce or remarriage need not lead to weakened family relations nor ultimately to marijuana use. Rather, strong relations between parents and adolescents can provide a buffer against associations with drug using peers and mari- 
juana use in both intact and disrupted families, and among both younger and older adolescents.

Appendix A. Characteristics of Family and Peer Scales

\begin{tabular}{|c|c|c|c|c|}
\hline & $\begin{array}{l}\text { Factor } \\
\text { loading }\end{array}$ & Mean & $S D$ & Alpha \\
\hline $\begin{array}{l}\text { Attachment } \\
\text { a. "I feel close to my family" } \\
\text { (five possible responses: } \\
\text { strongly agree-strongly } \\
\text { disagree) }\end{array}$ & -.612 & 21.90 & 4.13 & .75 \\
\hline $\begin{array}{l}\text { b. "I feel lonely when I'm with } \\
\text { my family" (five possible } \\
\text { responses: strongly agree- } \\
\text { strongly disagree }\end{array}$ & .427 & & & \\
\hline $\begin{array}{l}\text { c. "My family is not interested } \\
\text { in my problrms" (five possible } \\
\text { responses: strongly agree- } \\
\text { strongly disagree) }\end{array}$ & .654 & & & \\
\hline $\begin{array}{l}\text { d. "I feel like an outsider with } \\
\text { my family" (five possible } \\
\text { responses: strongly agree- } \\
\text { strongly disagree) }\end{array}$ & .640 & & & \\
\hline $\begin{array}{l}\text { e. "How are you doing at getting } \\
\text { along with your parents?" } \\
\text { (five possible responses: } \\
\text { very well-not well at all) }\end{array}$ & -.503 & & & \\
\hline $\begin{array}{l}\text { f. "How successful are your } \\
\text { parents at comforting you } \\
\text { when you are unhappy?" } \\
\text { (five possible responses: } \\
\text { very well-not well at all) }\end{array}$ & -.500 & & & \\
\hline $\begin{array}{l}\text { g. "My parents think I'm messed } \\
\text { up" (five possible responses: } \\
\text { strongly agree-strongly disagree }\end{array}$ & .441 & & & \\
\hline $\begin{array}{l}\text { Involvement } \\
\text { a. "How many afternoons } \\
\text { do you spend with } \\
\text { your family?" }(0-5)\end{array}$ & .743 & 11.23 & 3.12 & .69 \\
\hline $\begin{array}{l}\text { b. "How many evenings } \\
\text { do you spend with } \\
\text { your family?" }(0-5)\end{array}$ & .704 & & & \\
\hline $\begin{array}{l}\text { c. "How much time on } \\
\text { the weekends do you } \\
\text { spend with your family?" } \\
\text { (five possible responses: } \\
\text { great deal-very little) }\end{array}$ & .440 & & & \\
\hline
\end{tabular}




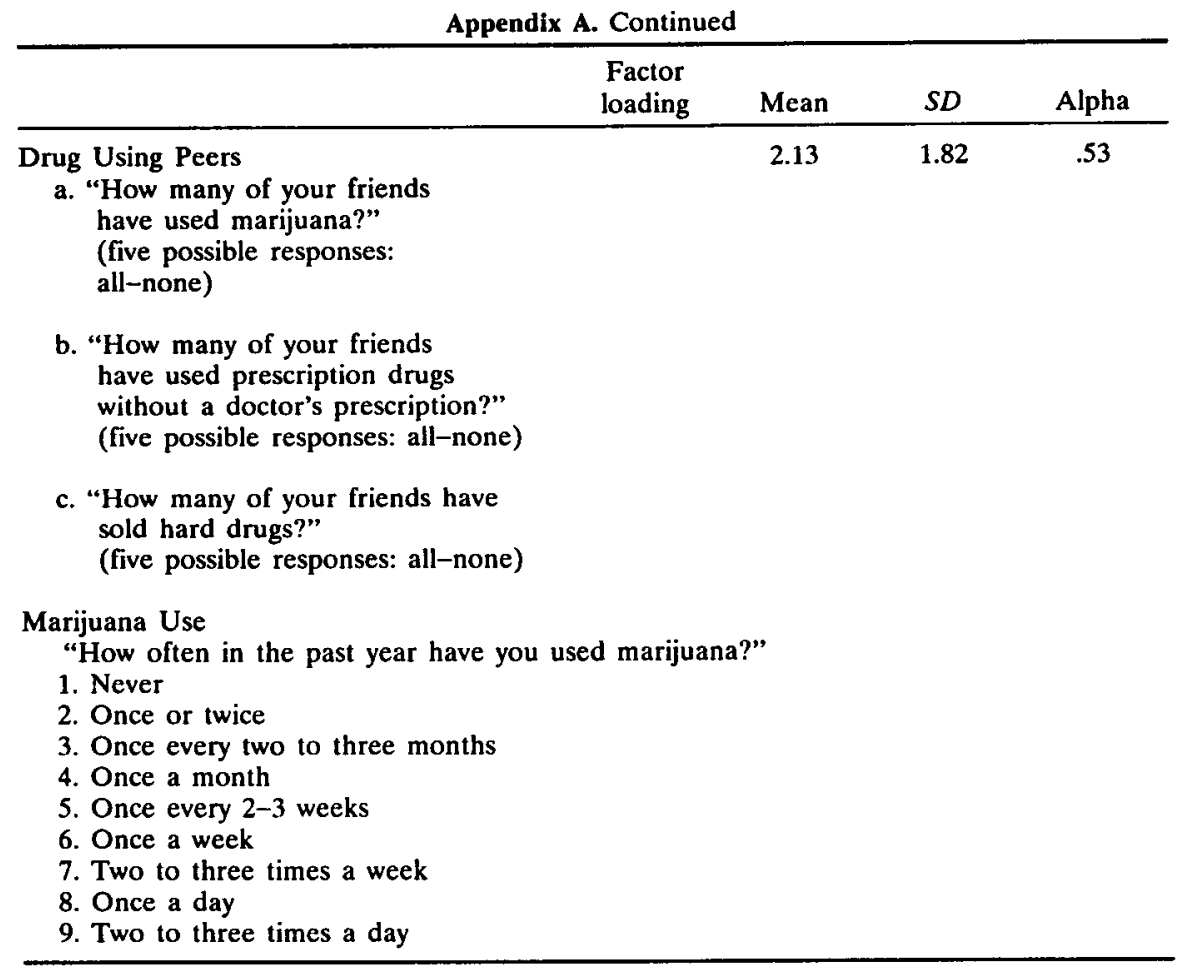

\section{REFERENCES}

Amato, P. R. (1987). Family processes in one-parent, stepparent, and intact families. J. Marriage Family 49: 327-337.

Amato, P. R., and Keith, B. (1991). Parental divorce and the well-being of children: A metaanalysis. Psychol. Bull. 110: 26-46.

Amemiya, T. (1985). Advanced Econometrics. Harvard University Press, Cambridge, MA.

Bailey, S. L., and Hubbard, R. L. (1990). Developmental variation in the context of marijuana initiation among adolescents. J. Health Social Behav. 31: 58-70.

Bailey, S. L., and Hubbard, R. L. (1991). Developmental changes in peer factors and the influence on marijuana initiation among secondary school students. J. Youth Adolesc. 20: 339-360.

Baron, R. M., and Kenny, D. A. (1986). The moderator-mediator distinction in social psychological research: Conceptual, strategic, and statistical considerations. J. Personal. Social Psychol. 51: 1173-1182.

Berk, R. A. (1983). An introduction to selection bias in sociological data. Am. Sociol. Rev. 48: 386-398.

Berndt, T. J. (1979). Developmental changes in conformity to peers and parents. Develop. Psychol. 15: 608-616. 
Block, J. H., Block, J., and Gjerde, P. F. (1986). The personality of children prior to divorce. Child Develop. 57: 827-840.

Brody, G. H., and Forehand, R. (1988). Multiple determinants of parenting: Research findings and implications for the divorce process. In Hertherington, E. M., and Arasteh, J. D. (eds.), Impact of Divorce, Single Parenting, and Stepparenting on Children. Lawrence Erlbaum, Hillsdale, NJ.

Brook, J. S., Brook, D. W., Gordon, A. C., Whiteman, M., and Cohen, P. (1990). The psychosocial etiology of adolescent drug use: A family interactional approach. Genet. Social Gen. Psychol. Monogr. 116: 111-267.

Cherlin, A. J., Furstenberg, F. F., Chase-Lansdale, P. L., Kiernan, K. E., Robins, P. K., Morrison, D. R., and Teitler, J. O. (1991). Longitudinal studies of effects of divorce on children in Great Britain and the United States. Science 252: 1386-1389.

Cohen, A. (1983). Comparing regression coefficients across subsamples: A study of the statistical test. Sociol. Res. Methods 12: 77-94.

DeFleur, L. B. (1975). Biasing influences on drug arrest records: Implications for deviance research. Am. Sociol. Rev. 40: 88-103.

Dishion, T. J., and Loeber, R. (1985). Adolescent marijuana and alcohol use: The role of parents and peers revisited. Am. J. Drug Alcohol Abuse 11: 11-25.

Doherty, W. J., and Needle, R. H. (1991). Psychological adjustment and substance use among adolescents before and after a parental divorce. Child Develop. 62: 328-337.

Elliott, D. S., Ageton, S. S., Huizinga, D., Knowles, B., and Canter, R. (1983). The prevalence and incidence of delinquent behavior, 1976-1980. Project Report No. 26, Behavioral Research Institute, Boulder, CO.

Elliott, D. S., Huizinga, D., and Ageton, S. S. (1985). Explaining Delinquency and Drug Use. Sage Publications, Newbury Park, CA.

Farnworth, M. (1984). Family structure, family attributes, and delinquency in a sample of low-income, minority males and females. J. Youth Adolesc. 13: 349-364.

Flewelling, R. L., and Bauman, K. E. (1990). Family structure as a predictor of initial substance use and sexual intercourse in early adolescence. J. Marriage Family 52: 171181 .

Forehand, R., Long, N., and Brody, G. (1988). Divorce and marital conflict: Relationship to adolescent competence and adjustment in early adolescence. In Hetherington, E. M., and Arasteh, J. D. (eds.), Impact of Divorce, Single Parenting, and Stepparenting on Children. Lawrence Erlbaum, Hillsdale, NJ.

Forgatch, M. S., Patterson, G. R., and Skinner, M. L. (1988). A mediational model for the effect of divorce on antisocial behavior in boys. In Hetherington, E. M., and Arasteh, J. D. (eds.), Impact of Divorce, Single Parenting, and Stepparenting on Children. Lawrence Erlbaum, Hillsdale, NJ.

Furstenberg, F. F., and Cherlin, A. J. (1991). Divided Families: What Happens to Children When Parents Part. Harvard University Press, Cambridge, MA.

Ginsberg, I. J., and Greenley, J. R. (1978). Competing theories of marijuana use: A longitudinal study. J. Health Social Behav. 19: 22-34.

Glenn, N. D., and Shelton, B. A. (1983). Preadult background variables and divorce: A note of caution about overreliance on explained variance. J. Marriage Family 45: 405-410.

Hetherington, E. M. (1987). Family relations six years after divorce. In Pasley, K., and Ihinger-Tallman, M. (eds.), Remarriage and Stepparenting Today: Current Research and Theory. Guilford Press, New York.

Hetherington, E. M., Cox, M., and Cox, R. (1982). Effects of divorce on parents and children. In Lamb, M. (ed.), Nontraditional Families: Parenting and Child Development. Lawrence Erlbaum, Hillsdale, NJ.

Hetherington, E. M., Stanley-Hagan, M., and Anderson, E. R. (1989). Marital transitions: A child's perspective. Am. Psychol. 44: 303-312.

Hirschi, T. (1969). Causes of Delinquency. University of California Press, Berkeley, CA.

Huba, G. J., and Bentler, P. M. (1980). The role of peer and adult models for drug taking at different stages in adolescence. J. Youth Adolesc. 9: 449-465. 
Hundlesby, J., and Mercer, G. W. (1987). Family and friends as social environments and their relationship to young adolescents' use of alcohol, tobacco, and marijuana. J. Marriage Family 49: 151-164.

Thinger-Tallman, M. (1988). Research on stepfamilies. Ann. Rev. Sociol. 14: 25-48.

Jensen, G., and Brownfield, D. (1982). Parents and drugs: specifying the consequences of attachment. Criminology 21: 543-554.

Johnson, R. E. (1986). Family structure and delinquency: General patterns and gender differences. Criminology 24: 65-84.

Johnson, R. E., Marcos, A. C., and Bahr, S. J. (1987). The role of peers in the complex etiology of adolescent drug use. Criminology 25: 323-339.

Kandel, D. B. (1978). Homophily, selection, and socialization in adolescent friendship. Am. J. Sociol. 84: 427-436.

Kandel, D. B. (1980). Drug and drinking behavior among youth. Ann. Rev. Sociol. 6: 235-285.

Kandel, D. B., Kessler, R. C., and Margulies, R. Z. (1978). Antecedents of Adolescent Initiation into Stages of Drug Use: A Developmental Analysis. J. Youth and Adolesc. 7: 13-40.

Kellam, S. G., Adams, R., Brown, C. H., and Ensminger, M. E. (1982). The Long-Term Evolution of the Family Structure on Teenage and Older Mothers. J. Marriage Family 44: 539-554.

LaGrange, R. L., and White, H. R. (1985). Age differences in delinquency: A test of theory. Criminology 23: 19-45.

Lehman, D. R., Lang, E. L., Wortman, C. B., and Sorenson, S. B. (1989). Long term effects of sudden bereavement: Marital and parent-child relationships and children's reactions. J. Family Psychol. 2: 344-367.

Liska, A. E., and Reed, M. D. (1985). Ties to conventional institutions and delinquency: Estimating reciprocal causal effects. Am. Sociol. Rev. 50: 547-560.

Little, R. (1985). A note about models for selectivity bias. Econometrica 53: 1469-1474.

Loeber, R., and Stouthamer-Loeber, M. (1986). Family factors as correlates and predictors of juvenile conduct problems and delinquency. In Tonry, M., and Morris, N. (eds.), Crime and Justice: An Annual Review of Research (Vol. 7). University of Chicago Press, Chicago.

Maddala, G. S. (1983). Limited-Dependent and Qualitative Variables in Econometrics. Cambridge University Press, Cambridge.

Matsueda, R. L., and Heimer, K. (1987). Race, family structure, and delinquency: A test of differential association and social control theories. Am. Sociol. Rev. 52: 826-840.

Mednick, B. R., Baker, R. L., and Carothers, L. E. (1990). Patterns of family instability and crime: The association of timing of the family's disruption with subsequent adolescent and young adult criminality. J. Youth Adolesc. 19: 201-220.

Menard, S. (1991). Longitudinal Research. Sage University Paper Series on Quantitative Applications in the Social Sciences, 07-076. Sage Publications, Newbury, Park, CA.

Needle, R. H., Su, S. S., and Doherty, W. (1990). Divorce, remarriage, and adolescent substance use: A prospective longitudinal study. J. Marriage Family 52: 157-169.

Nelson, G. (1982). Coping with the loss of father: Family reaction to death or divorce. $J$. Family Issues 3: 41-60.

Peterson, J. L., and Zill, N. (1986). Marital disruption, parent-child relationships, and problem behavior in children. J. Marriage Family 48: 295-307.

Plewis, I. (1985). Analyzing Change: Measurement and Explanation Using Longitudinal Data. John Wiley \& Sons, New York.

Selnow, G. (1987). Parent-child relationships and single and two parent families: Implications for substance usage. J. Drug Educat. 17: 315-326.

Simons, R. L., and Robertson, J. F. (1989). The impact of parenting factors, deviant peers, and coping style upon adolescent drug use. Family Relat. 38: 273-281.

Smith, D. A., and Paternoster, R. (1987). The gender gap in theories of deviance: Issues and evidence. J. Res. Crime Delinq. 24: 140-172.

Thomberry, T. P. (1987). Toward an interactional theory of delinquency. Criminology 25: 863891. 
Thornberry, T. P., Lizotte, A. J., Krohn, M. D., Farnworth, M., and Jang, S. J. (1991). Testing interactional theory: An examination of reciprocal causal relationships among family, school, and delinquency. J. Crim. Law Criminol. 82: 3-35.

Tobin, J. (1958). Estimation of relationships for limited dependent variables. Econometrica 26: 24-36.

Van Voorhis, P., Cullen, F., Mathers, R., and Garner, C. C. (1988). The impact of family structure and quality on delinquency: A comparative assessment of structural and functional factors. Criminology 26: 235-261.

Wallace, J. M., and Bachman, J. G. (1991). Explaining racial/ethnic differences in adolescent drug use: The impact of background and lifestyle. Social Problems 38: 333-357.

Wallerstein, J. S., and Kelly, J. B. (1980). Surviving the Breakup: How Children and Parents Cope With Divorce. Basic Books, New York.

Wells, L. E., and Rankin, J. H. (1991). Families and delinquency: A meta-analysis of the impact of broken homes. Social Problems 38: 71-93.

White, H. R., Pandina, R., and LaGrange, R. L. (1987). Longitudinal predictors of serious substance use and delinquency. Criminology 25: 715-740.

Zill, N. (1988). Behavior, achievement, and health problems among children in stepfamilies: Findings from a national survey of child health. In Hetherington, E. M., and Arasteh, J. D. (eds.), Impact of Divorce, Single Parenting, and Stepparenting on Children. Lawrence Erlbaum, Hillsdale, NJ. 